\title{
$\operatorname{CONF}-951155-7$ 5AND95-1789C
}

\section{NEW MATERIALS FOR ORGANIC LIGHT-EMITTING DIODES}

\author{
S. Joshua Jacobs, Timothy P. Pollagi, and Michael B. Sinclair \\ Sandia National Laboratories, Albuquerque, New Mexico 87185
}

Rodger D. Scurlock and Peter R. Ogilby

Department of Chemistry, University of New Mexico, Albuquerque, New Mexico 87131

\begin{abstract}
We have investigated the performance of a class of heterocycles, 5,10-dihetera5,10-dihydroindeno[3,2b]indenes, as hole transport agents in simple double heterostructure organic light-emitting diodes with tris(8-hydroxyquinoline)aluminum (Alq). The best of these materials, 5,10-dihydroindolo[3,2b]indole, yields devices with luminance and lifetimes comparable to those obtained using $\mathrm{N}, \mathrm{N}^{\prime}$-di-(3-methylphenyl)-N, $\mathrm{N}^{\prime}$ diphenyl-4,4'-diaminobiphenyl (TPD) as a hole transporting material.
\end{abstract}

\section{INTRODUCTION}

Three prerequisites of materials to be used in organic light-emitting diodes (LEDs) are solid-state fluorescence, good charge mobility, and resistance to oxidative degradation. Poly (p-phenylene vinylene) (PPV) certainly meets the first two requirements, but physical and chemical studies in these labs and elsewhere have highlighted decomposition of PPVtype materials as a potential failure mechanism in organic LEDs. ${ }^{1,2}$ Recent work ${ }^{2}$ has shown that singlet oxygen $\left({ }^{1} \mathrm{O}_{2}\right)$ is an intermediate in this process in the case of BCHAPPV, a cholestanoxy-substituted PPV, and in fact that BCHA-PPV is a good sensitizer for ${ }^{1} \mathrm{O}_{2}$. With these observations, study of the factors involved in ${ }^{1} \mathrm{O}_{2}$ sensitization and design of electroluminescent molecules and materials that resist oxdative degradation have become important problems.

In this study, two members of the general class of 5,10-dihetera-5,10dihydroindeno[3,2b]indenes, potential hole-transporting replacements for PPV, have been examined. Specifically, these materials are indoloindole 1a and thianapthindole 2a, which may satisfy all three prerequisites mentioned above. Each of these materials contains a stilbene chromophore, but one that is incorporated into and possibly stabilized against oxidative degradation by an aromatic ring system. It has been observed experimentally that environmentally stable nitrogen-centered radical cations are formed in $\mathrm{N}, \mathrm{N}^{\prime}$ dimethylindolo[3,2b]indole $\mathbf{1 b}$, supporting the potential hole-transporting properties of this class of compounds. ${ }^{3}$ In fact, the hole-transport properties of $2 \mathrm{a}$ have been studied previously, and 2a is a good hole transporting material. ${ }^{4}$ Compound $\mathbf{1 b}$ is known to be highly fluorescent in solution, ${ }^{3}$ and we have found that $1 \mathrm{a}$ and $1 \mathrm{~b}$ are also fluorescent in the solid state. 


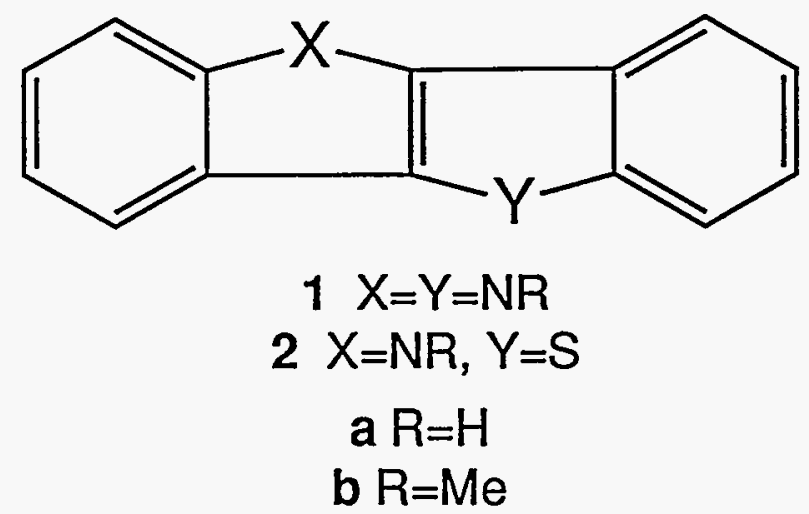

\section{EXPERIMENTAL SECTION}

\section{5,10-dihydroindolo[3,2b]indole (1a) was prepared by the method of Dougherty. ${ }^{5}$}

Thianapthindole (2a) Ethyl acetoacetate ( $12 \mathrm{~g}, 92 \mathrm{mmol}$ ) was added slowly via pipette to a mixture of thiosalicylic acid $(10 \mathrm{~g}, 65 \mathrm{mmol})$ and sulfuric acid $(65 \mathrm{ml})$ contained in an Erlenmeyer flask. When addition was complete, the mixture was heated to $45^{\circ} \mathrm{C}$ for two hours and then allowed to cool to room temperature. The mixture was poured onto ice and the yellow-brown solid that was formed was filtered and steam distilled. A slightly pink solid collected in the receiver and was immediately mixed with excess phenylhydrazine in acetic acid. After standing overnight, a precipitate had formed. The solid was collected by filtration, washed with acetic acid and then with water, recrystallized from ethanol, and sublimed to yield $2 \mathrm{a}, 2.7 \mathrm{~g}, 19 \%$ yield (mp $250-1^{\circ} \mathrm{C}$, lit. $^{6} 251-2^{\circ} \mathrm{C}$ ).

Physical Measurements Amorphous thin films of 1a and 2a were prepared by resistive heating in a bell-jar evaporator with a base pressure $<5 \times 10^{-5}$ torr. For photoluminescence measurements, films were prepared on fused silica substrates, while for measurements of the photoconductivity of 1a, thin films were deposited on ITO coated glass and aluminum electrodes were then deposited by evaporation. Photoluminescence measurements were conducted such that $>99 \%$ of the incident light was absorbed, and emission was measured with an integrating sphere. Photoconductivity was measured by a time-of-flight technique that has been described elsewhere.?

Diode Fabrication and Testing The devices studied were fabricated in a bell jar evaporator. Organic materials were evaporated by resistive heating and deposited on $1 "$ square ITO substrates. The thicknesses were hole transport material: $700 \AA$, Alq: $500 \AA$. A $200 \AA$ layer of $\mathrm{Mg}$ was deposited, followed by a $2000 \AA$ layer of silver to protect the cathode from oxidation. A shadow mask was used to control the deposition pattern of the metals. The devices formed were oval in shape and had an area of $5 \mathrm{~mm}^{2}$. The device was transferred from the evaporator to a custom vacuum cell, and measurements of device performance were conducted under a dynamic vacuum. The pressure in the cell during testing was below $1 \times 10^{-4}$ torr.

\section{RESULTS AND DISCUSSION}

Synthesis A facile synthesis of compounds 1a based on Pd-catalyzed coupling of 1-iodo2-nitrobenzene has recently been reported. ${ }^{5}$ Compound 2 a can be prepared by modification of a much older synthesis described by McClelland. ${ }^{6}$ Steam distillation is essential to the 
isolation of the intermediate benzothiophen-3-one, which is then condensed in a Fischer indole synthesis with phenylhydrazine in acetic acid.

Photoluminescence The solid state photoluminescence efficiencies of compounds $1 \mathrm{a}$ and 2a have been measured for evaporated thin films with a thickness of approximately 3000 $\AA$. The quantum yield of fluorescence for $1 \mathrm{a}, 8.7 \%$, is comparable to that observed in our laboratory for both PPV (8\%) and tris(8-hydroxyquinoline)aluminum (Alq) (12\%), while that for $2 \mathrm{a}$ is $2.7 \%$. The difference between the values for $1 \mathrm{a}$ and $2 \mathrm{a}$ can be attributed to a heavy atom effect.

Photoconductivity The photoconductivity of $1 \mathrm{a}$ has been measured in an evaporated thin film sandwiched between ITO and aluminum electrodes. The value of the hole mobility, $1 \times 10^{-4} \mathrm{~cm}^{2} \mathrm{~V}^{-1} \mathrm{~s}^{-1}$ at a field of $1 \times 10^{5} \mathrm{~V} \mathrm{~cm}^{-1}$, shows that holes are easily transported in this material. Good hole mobility in 2 a has been demonstrated previously. ${ }^{4}$

Singlet oxygen chemistry The relative stabilities of these materials under steady-state irradiation in the presence of oxygen reveal that they are substantially less sensitive to degradation by photooxidation than BCHA-PPV in both Rose Bengal-sensitized and selfsensitized experiments. The overall bleaching rate constants for $1 \mathrm{a}$ and $\mathbf{2 a}$ are one to two orders of magnitude lower than for BCHA-PPV. The enhanced stability is attributed in part to the amine function, as amines'are good physical quenchers of ${ }^{1} \mathrm{O}_{2}$. Absolute kinetic studies are underway.

Electroluminescence Heterostructure devices have been made using 1a as the hole transporting layer, with Alq as the electron transporting layer, an ITO anode and Mg cathode. The electroluminescence spectra (Figure 1) of these devices indicate that the

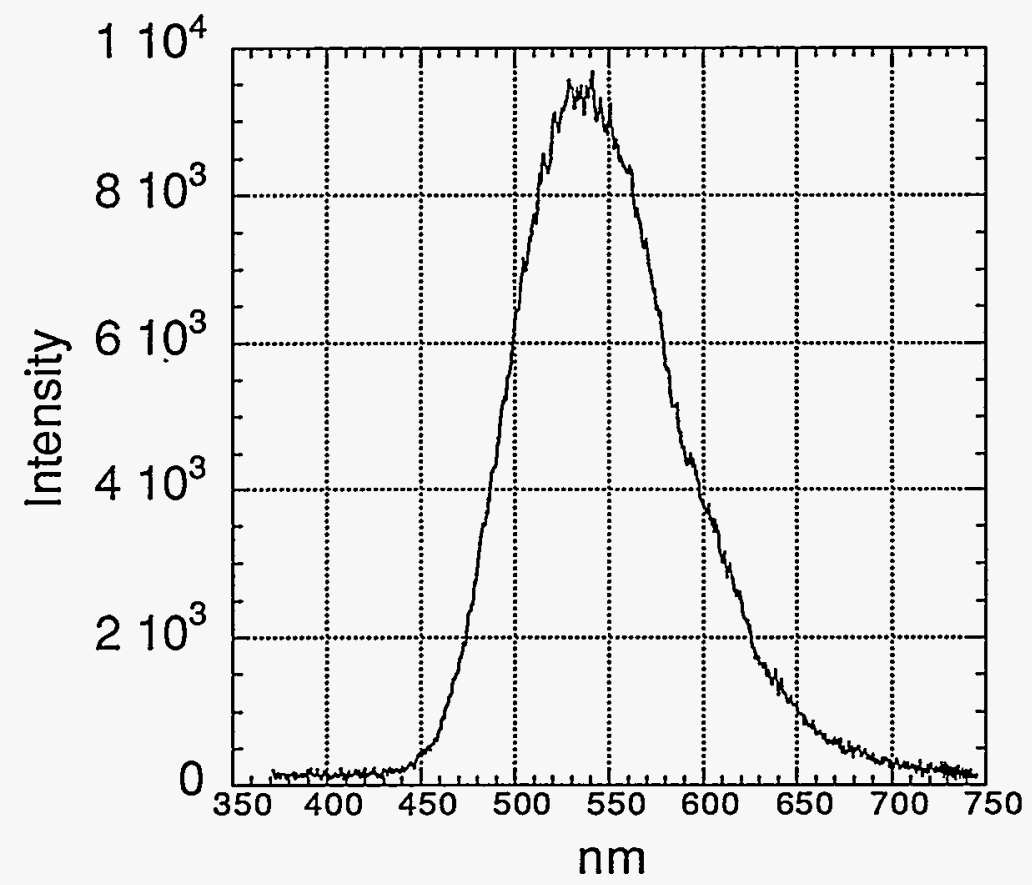

Figure 1. Electroluminescence spectrum of $\mathrm{ITO} / \mathrm{1a} / \mathrm{Alq} / \mathrm{Mg} / \mathrm{Ag}$ device 
observed light is due to Alq emission, and the intensity of the observed light in our devices typically shows brightness of $200-250 \mathrm{~cd} \mathrm{~m}^{-2}$ with a current density of $20 \mathrm{~mA} \mathrm{~cm}^{-2}$ in constant current mode. These conditions require a $7 \mathrm{~V}$ driving voltage. By comparison, devices fabricated with TPD and operated under the same conditions show a brightness of $600 \mathrm{~cd} \mathrm{~m}^{-2}$ and a driving voltage of $6 \mathrm{~V}$. We expect to increase the efficiency through improvements in our device fabrication process. Current-voltage curves for devices made using 1a are shown in Figure 2.
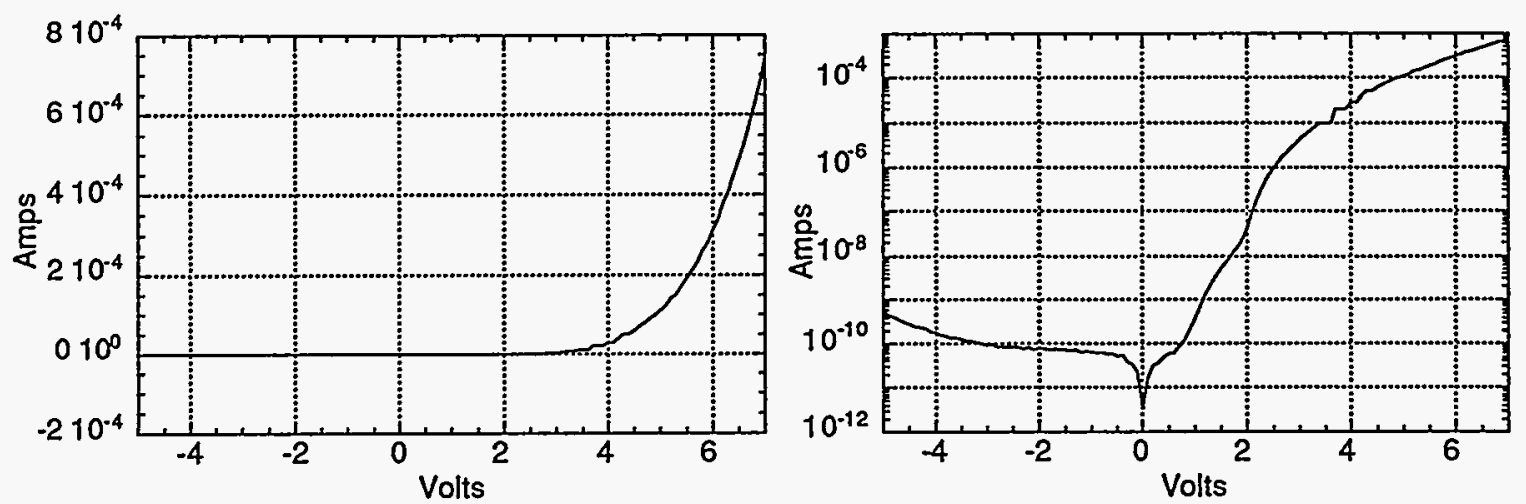

Figure 2. I-V curves for ITO/1a/Alq/Mg/Ag device

\section{CONCLUSIONS}

Two members of a class of compounds capable of functioning as hole-transporting agents in organic LEDs have been synthesized, and experiments show that they are more resistant to photooxidative degradation than BCHA-PPV. Compound 1a has been used in the fabrication of an efficient green-emitting LED.

\section{ACKNOWLEDGEMENTS}

This work was supported at Sandia National Laboratories by the United States Department of Energy under contract number DE-AC04-94AL85000 and at the University of New Mexico by the National Science Foundation under grant number CHE-9402145. We thank Paul Beeson and Gary Jones for technical assistance.

\section{REFERENCES}

1. M. Yan, L. J. Rothberg, F. Papadamitrakopoulos, M. E. Galvin, T. M. Miller, Phys. Rev. Lett. 73, 744-747 (1994).

2. R. D. Scurlock, B. Wang, P. R. Ogilby, J. R. Sheats, and R. L. Clough, J. Am. Chem. Soc. 117, 10194-10202 (1995).

3. S. Hünig and H.-C. Steinmetzer, Liebigs Ann. Chem. 1976, 1090-1102.

4. W. Stampor, J. Kalinowski, and P. Di Marco, Chem. Phys. 134, 385-393 (1989).

5. M. M. Murray, P. Kaszynski, D. A. Kaisaki, W. Chang, and D. A. Dougherty, J. Am. Chem. Soc. 116, 8152-8161 (1994).

6. E. W. McClelland and F. D'Silva, J. Chem. Soc. 227-230 (1932).

7. R. G. Kepler, P. M. Beeson, S. J. Jacobs, R. A. Anderson, M. B. Sinclair, V. S. Valencia, and P. A. Cahill, Appl. Phys. Lett. 66, 3618-3620 (1995). 


\section{DISCLAIMER}

This report was prepared as an account of work sponsored-by an agency of the United States Government. Neither the United States Government nor any agency thereof, nor any of their employees, makes any warranty, express or implied, or assumes any legal liability or responsibility for the accuracy, completeness, or usefulness of any information, apparatus, product, or process disclosed, or represents that its use would not infringe privately owned rights. Reference herein to any specific commercial product, process, or service by trade name, trademark, manufacturer, or otherwise does not necessarily constitute or imply its endorsement, recommendation, or favoring by the United States Government or any agency thereof. The views and opinions of authors expressed herein do not necessarily state or reflect those of the United States Government or any agency thereof. 